\title{
Hallazgos histopatológicos de biopsias endometriales en puerperio normal
}

\author{
Daniel Beltrán*; Laritza Rodríguez V.**; Luis Amaya; Fernando Gómez C.***
}

\section{RESUMEN}

OBJETIVOS: Se trata de describir los cambios histopatológicos encontrados en biopsia de endometrio en pacientes en puerperio normal y compararlos con los de pacientes con infección puerperal.

MATERIAL Y METODOS: Se tomaron 15 pacientes en puerperio clínicamente normal para practicarles biopsia de endometrio en los días décimo, vigésimo y trigésimo post-parto. Cuyo parto había sido atendido en el Servicio de Obstetricia del Hospital de San José entre enero y junio de 1992. El otro grupo de pacientes está constituido por 15 pacientes con diagnóstico de infección uterina puerperal.

RESULTADOS: Los hallazgos histopatológicos de los dos grupos de pacientes no difieren. En ambos grupos se encuentra necrosis e infiltrado inflamatorio agudo determinado por la presencia de plasmocitos, macrófagos y polimorfonucleares neutrófilos. Al igual de grados variables de depósitos de fibrina y decidua necrótica. Como reporte patológico final tenemos en todas las pacientes: "endometritis subaguda post-parto" " “endometritis aguda post-parto” a los diez y veinte días del parto. Al día trigésimo se encuentran diversos grados de endometrio proliferativo.

CONCLUSION: Es imposible determinar por histopatología el diagnóstico de endometritis post parto ya que los hallazgos al microscopio no aportan parámetros de diferenciación. El diagnóstico se establece por clínica y paraclínica.

PALABRAS CLAVES: Endometrio, decidua, endometritis puerperal.

\section{SUMMARY}

OBJECTIVES: The purpuse of the present study was to describe the histopathologic changes found in the endometrial biopsy in patients in normal puerperium and to compare them with patients with puerperal infection of the uterus.

MATERIAL AND METHODS: 15 pacients in normal puerperium where studied and an emdometrium biopsy taken during the days ten, twenty and thirthy post partum. The delivery had been attended in the Obstetrical Services of the San José Hospital of Bogotá between january and june of 1992. The other group of patients where 15 patients with clinical diagnosis of uterine puerperal infection.

RESULTS: The histopathologic findings of the two groups of patients did not show any difference. In both groups we found necrosis and acute inflamatory infiltrate determined by the presence of white blood cells, necrotic decidua, and variable states of fibrin deposits. As a final pathologic report we had in all the patients "subacute post partum endometritis" and acute post partum endometritis at ten, twenty day post partum. At day thirthy we found different grades of proliferative endometrium.

CONCLUSIONS: It is imposible to determine by histopathologic findings the diagnosis of post partum endometritis the histopathologic changes do not have clear guidelines for differentiation. The diagnosis can only be established by clinical and paraclinical findings.

KEY WORDS: Endometrium, decidua, endometritis puerperal.

Hace 200 años el médico escocés Alexander Gordon observó que la fiebre puerperal podía transmitirse de una enferma a otra. Sólo 50 años después Semmelweis y Holmes llegaron a la conclusión que el mismo médico era el vehículo transmisor y establecieron el simple lavado de las manos antes de realizar la exploración como medio de control de las epidemias. Pocos años después Pasteur

\footnotetext{
* Instructor Asistente Director Ginecología Hospital San José ** Jefe Servicio de Obstetricia.

*** Profesor Asociado.

Departamentos de Gineco-Obstetricia y Patología. Hospital de San José. Universidad del Rosario.
}

aisló el Estreptococo hemolítico patógeno e inició la era del estudio y tratamiento de la infección obstétrica.

Hoy en día la infección puerperal continúa siendo causa de morbimortalidad importante siendo reportada entre un 2 y $8 \%$ a pesar del uso de antibióticos y el manejo precoz de las causas de infección en la paciente obstétrica, pe. ruptura prematura de membranas, retención de restos ovulares, etc.

En el Departamento de Obstetricia y Ginecología del Hospital de San José la incidencia de infección obstétrica es del 2.5\% (1). El diagnóstico se establece con base en datos clínicos y paraclínicos, la presencia de fiebre mayor de $38^{\circ} \mathrm{C}$, signos abdominales inespecíficos que van desde la normalidad hasta hiperestesia uterina exqui- 
sita, peritonitis difusa y distensión marcada. La exploración pélvica muestra signos variables, en los casos leves sólo puede existir hiperestesia uterina ligera y loquios en apariencia normales. En casos más avanzados se encontrará calor local con hiperestesia uterina difusa y loquios francamente fétidos especialmente en los casos de infección por gérmenes anaerobios. El retraso en la involución uterina y en la formación del cuello también son parámetros importantes en el diagnóstico. El cuadro hemático muestra leucocitosis marcada con aparición a las formas inmaduras. Los hematocríticos seriados pueden mostrar disminución en forma inexplicada. Los gérmenes causales se aislan tomando muestras adecuadas de la cavidad uterina evitando al máximo la contaminación con secreciones vaginales.

Las bacterias más frecuentes reportadas en literatura mundial como agentes etiológicos en la endometritis puerperal son Escherichia Coli, Enterococos del Grupo D, y como anaerobios los Bacteroides, los Peptococos y los Mycoplasmas genitales (2).

En nuestro hospital los gérmenes reportados con mayor frecuencia son: Estreptococo fecalis, E. Coli, Gardenella Vaginalis y Estreptococo del Grupo B (1).

El diagnóstico final de endometritis puerperal generalmente se confirma por los hallazgos histopatológicos del material obtenido en el legrado uterino que se practica como parte del tratamiento de la enfermedad. Al realizar una revisión de la literatura médica mundial, no encontramos datos al respecto de cambios histopatológicos en la decidua de pacientes en puerperio normal.

Dentro de la escasa literatura encontrada, un breve aparte del libro del Dr. R. Schwarcz (4) afirma que "la regeneración del endometrio se realiza a expensas del epitelio de los fondos de saco glandulares de la parte profunda de la caduca, este epitelio entra en proceso de proliferación, las células pasan de cúbicas a cilíndricas y desbordan el conducto glandular. La cavidad uterina está tapizada en los primeros días por una capa delgada de fibrina, que recubre a una capa más o menos espesa de células deciduales en vías de histólisis. La capa de fibrina y las células deciduales son eliminadas con los loquios. Las células de los fondos de saco glandulares comienzan a multiplicarse desde el sexto día para regenerar el endometrio. La cicatriz dejada por la placenta presenta una zona de infiltración leucocitaria que circunda a los orificios vasculares trombosados".

La fálta de datos bibliográficos en la literatura, nos indujo a realizar el presente estudio con el fin de intentar establecer las características histológicas normales de la decidua en el puerperio libre de infección, y así lograr establecer la diferenciación histológica con los casos clínicamente manifiestos.

\section{Material y métodos}

Fueron incluidas en el estudio un grupo de 15 pacientes escogidas al azar cuyo parto fue atendido en el Servicio de Obstetricia del Hospital de San José durante el período comprendido entre enero a junio de 1992. Determinaban criterios de inclusión al estudio la ausencia total de factores de riesgo para infección tales como:
- Ruptura prematura de membranas mayor de 6 horas antes del parto.

- Signos clínicos de infección durante los primeros 10 días de puerperio.

- Parto instrumentado.

- Complicaciones hemorrágicas del post-parto.

- Desgarros perineales y/o cervicales.

- Retención de restos placentarios.

Les fue practicada biopsia de endometrio al día décimo, vigésimo y trigésimo del parto. Muestra obtenida previa especuloscopia y rigurosa asepsia y antisepsia del cérvix. Pinzamiento del labio anterior con pinza de cuello y toma de la muestra con cureta de Novak.

Las muestras fueron procesadas por el laboratorio de patología del Hospital.

En ninguna de las pacientes se presentó complicación alguna, existiendo en general adecuada aceptación al procedimiento.

El otro grupo está conformado por 15 pacientes con diagnóstico de endometritis post-parto, con manifestaciones clínicas dadas por fiebre, subinvolución uterina, cervical y loquios fétidos. Dentro de los parámetros paraclínicos se encuentran leucocitosis mayor de 16.000 , con desviación a la izquierda, cultivos endometriales positivos. A estas pacientes les fue practicado legrado uterino como parte del tratamiento de la endometritis.

\section{Resultados}

Los hallazgos microscópicos obtenidos en las deciduas de las pacientes del primer grupo mostraban necrosis e infiltrado inflamatorio agudo determinado por la presencia de plasmocitos, macrófagos y polimorfonucleares neutrófilos. Al igual de grados variables de depósitos de fibrina y decidua necrótica. Como reporte patológico final tenemos en todas las pacientes : "endometritis subaguda post-parto" y "endometritis aguda post-parto" a los diez y veinte días del parto.

En los resultados obtenidos a los treinta días del parto tenemos patrón glandular proliferativo en estroma fuso celular con presencia de escasos polimorfonucleares y plasmocitos. Existiendo aún algún grado de infiltrado inflamatorio y fases iniciales de endometrio proliferativo.

En las pacientes con diagnóstico clínico y paraclínico de endometritis post-parto los hallazgos patológicos fueron iguales. En todas ellas se encontró infiltrado inflamatorio agudo con polimorfonucleares, fragmentos de decidua necrótica y extensas áreas hemorrágicas.

\section{Conclusiones}

Del presente estudio comparativo podemos concluir que no existen parámetros histopatológicos para establecer el diagnóstico diferencial entre endometritis infecciosa puerperal clínicamente manifiesta y la decidua de un puerperio clínicamente normal.

Los muy escasos datos que tenemos en la literatura acerca de la histología de la decidua puerperal normal confirman los hallazgos de infiltrado inflamatorio obtenidos por nosotros, pero no tenemos ninguna fuente que 
determine claramente la diferencia histológica entre uno y otro grupo de pacientes.

Siendo la presentación clínica del cuadro de infección endometrial poco específica y habiéndonos apoyado siempre en la confirmación histológica para el diagnóstico final, con los hallazgos del presente estudio concluimos que en el momento no contamos con parámetro confirmatorio alguno para establecer el diagnóstico preciso.

Faltaría por aclarar cuál es el factor que determina que en pacientes con hallazgos histológicos similares las manifestaciones clínicas sean tan diferentes de un grupo a otro. Porqué algunas muestran signos claros de compromiso sistémico y de infección genital mientras que otras cursan asintomáticas.

Los presentes hallazgos tal vez sean la explicación del por qué algunos grupos de investigadores (hallazgos aún no publicados) han encontrado que la evolución de las pacientes con diagnóstico clínico de endometritis es similar en aquellas a quienes se les practica legrado uterino y en aquellas a quienes solamente se le aplica antibióticoterapia y oxitóxicos.

\section{BIBLIOGRAFIA}

1. Rodríguez F. Toro. Estudio prospectivo comparativo de uso de antibióticoterapia profiláctica en cesárea.

2. Newton N. Manejo de las complicaciones Ginecológicas y Obstétricas. Saunders Company. 1988; 370-372.
3. Monif G. Enfermedades Infecciosas en Obstetricia y Ginecología. Ed. Salvat. 1985; 367-378.

4. Schwarcz R. Obstetricia. Ateneo. 4ª Edición, 1987; 392-398.
Correos de Colombia

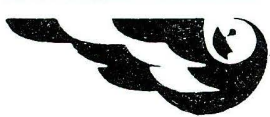

- SERVICIO ENCOMIENDAS ASEGURADAS

- SERVICIO CARTAS ASEGURADAS

- SERVICIO DE GIROS

- BUROFAX

- SERVICIO "CORRA"

- SERVICIO DE CORREO ORDINARIO

\section{Estos son nuestros servicios ¡utilicelos!}

- SERVICIO DE CORREO CERTIFICADO

- SERVICIO DE CERTIFICADO ESPECIAL

- ENCOMIENDAS CONTRA REEMBOLSO

- SERVICIO TARIFA POSTAL REDUCIDA

- SERVICIO DE FILATELIA

- SERVICIO ELECTRONICO

- SERVICIO INTERNACIONAL APR/SAL

- SERVICIO RESPUESTA COMERCIAL

- SERVICIOS ESPECIALES

Teléfonos para quejas y reclamos: 3340304 - 3415536 - Santafé de Bogotá, D.C. - Colombia

Cuente con nosotros hay que creer en los Correos de Colombia 